\title{
Adequacy of Quality Provisions in Standard Forms of Local and International Construction Contracts
}

\author{
Kwang,Q.W., , Ting, S. N ${ }^{2}$
}

\begin{abstract}
Standard forms of contracts have been in use in the Malaysian construction industry as a means to expedite contractual and legal duties for the clients who wish to avoid expensive and complex legal endeavors to arrive at an agreement with their contractors. Various forms have been drafted by various professional bodies and organizations, both locally and internationally, to meet the demands of the local construction market for standard forms. Quality provisions are among the topics/issues covered in the standard forms. However, evidently, it is noted that the quality and its standards in the Malaysian construction industry has consistently remained as the root for many construction disputes. Whether or not standard forms of construction contracts have sufficiently cater for quality, remains a question. If the "one-size fits all" postulate does not hold especially when it comes to ensuring quality on site, the question of validity and effectiveness of standard forms becomes a pertinent one. This paper presents a study of various quality related clauses in local and international standard forms and comparisons were made among the chosen forms. Experts opinion within this field are sought as well in order to improve the robustness of this study. This paper also investigates the adequacy of the provision of these forms and suggests suitable changes to the current standard forms, where necessary, within the study.
\end{abstract}

Keywords: Standard-forms, construction-contract, Quality

\section{INTRODUCTION}

contract is an enforceable agreement, which comes into effect when autonomous and definite parties come into consensus with the intention to create legal relations. According to the Contracts Act 1950, Section 2, an agreement is formed when an acceptance is expressed in pursuant to an offer/proposal made with the element of consideration i.e. a mutual exchange of something in value [9] Similarly, construction contracts abide by this tenet. Contracts may be drafted from scratch, i.e. "bespoke” forms, especially for mega projects like the KLIA project and the Petronas Twin Towers; but more commonly, using standard forms of construction contracts (hereinafter referred to as Standard Forms), [8] is the norm in the construction industry as there is no wish to start complex and expensive exercise of form drafting.

In Malaysia, the most common available standard forms are as follows:

i. $\quad$ Public Works Department or Jabatan Kerja Raya (PWD);

ii. $\quad$ Pertubuhan Arkitek Malaysia (PAM);

iii. $\quad$ Construction Industry Development Board (CIDB); and

iv. The Institute of Engineers, Malaysia (IEM);

The names of the standard forms are generally based on their acronym followed by the series and/or the year they are produced. These standard forms basically cover all the different type and nature of construction works and the procurement route used is usually the traditional general contracting method. Notwithstanding, under the same series of forms, certain forms also cover other procurement routes. For example, the PWD DBT is meant for Design Build and Turnkey projects, whilst the PWD 203N is meant for nominated subcontractors. For the purposes of this study, only standard forms with traditional general contracting will be discussed. The following local standard forms will be tenet of this paper's discussion: 
i. $\quad$ Standard Form of Contract to be used where Bills of Quantities Form Part of the Contract, PWD Form 203A (Rev. 2007) often referred as PWD 203A -2007

ii. $\quad$ Agreement and Conditions of PAM Contract 2006 (with Quantities) often referred as PAM 06

iii. $\quad$ CIDB Standard Form of Contract for Building Works - 2000 Edition commonly referred as CIDB 2000

In addition to the above local standard forms, the Federation Internationale des Ingénieurs-Conseils (FIDIC), the International Fédération of Consulting Engineers, also produces their own standard form; 1999 FIDIC Conditions of Contract for Construction (FIDIC form). Internationally, however, there are numerous other forms which have been produced but only the FIDIC form will be discussed here. The FIDIC form is chosen due to its recognition in the international arena, but most importantly it is the preferred form for World Bank and Asian Development Bank funded projects in Malaysia [9].

\section{PROBLEM STATEMENT}

Quality has never been a simple issue in construction works. Physical measurement and determination of quality have often been difficult. Construction defaults which made headlines like the Middle Ring Road II (MRR2) and the Highland Towers, gives rise to the question of the quality of workmanship. Whether it was that of a design fault, unexpected circumstances or by the forces of nature, the question remain whether our construction contracting system and contracts in particularly the standard forms have effectively catered for such events.

With quality related provisions in standard forms such as 'proper workmanlike and careful manner', 'recognised good practice' and 'properly equipped facilities', effective contract administration can be substantially hindered. These requirements often interpreted by the engineer in relation to the actual goods which are supplied and the work which is executed by the Contractor [12] can be deemed as subjective and ambiguous. The bottom line of this issue is whether the liability of quality has been properly expressed and clearly stated in our standard forms of construction contracts. It is true that the contractors could be liable for tort [13] and engineers can be sued for negligence. But whether such provisions like 'recognised good practice' or 'proper workmanlike and careful manner' are adequate and has achieved good contract administration on site, remains the issue.

\section{METHODOLOGY}

This study on adequacy of quality provisions is carried out based on careful clause study from the forms picked. This study will revolve around a central parameter for argument that is the "Adequacy" factor, which equates to the first the availability of provision and then the completeness of it (to cater for various aspects of contract administration of common problems on site). Clauses were then compared against one another before deciding on its adequacy. Semi-structured interviews and cases of disputes are included as part of the study in order to improve the robustness of the academic analyses of the clauses.

Quality provisions in the contract forms under study are split into the following:

- Material and Workmanship

- Testing and Inspection

- Performance Bond

- Disputes

\section{RESULTS AND ANALYSIS}

\subsection{Material and Workmanship}

The Material and Workmanship provisions in PWD 203A - 2007 maintain that quality is brought about by the control of materials and workmanship. The materials are determined by the Specification, whereby the variety and the standard of material or goods will be specified. Where it is not specified, it would be implied in law that the materials or good will be of good quality and the workmanship will be carried out with proper skill and care It is also important to read Clause 35.1 against the general law relating to construction and the primary obligation of the Contractor as per Clause 10.1. Hence, the Contractor is obliged to procure such materials of the specified standard unless granted permission by the Superintending Officer (SO). Failing to do so would lead to a breach of contract. Together with the materials is the need to produce the manufacturer's vouchers or certificates at the SO's request, to prove that the materials are indeed of the specified standard

PAM takes a more generic approach by including all the possible standards which could have been included in either of the subsidiary Contract Documents. As per clause 3.0, the Contract Documents include: the Letter of Award, the Articles of Agreement, the Conditions of Contract, the Contract Drawings, the Contract Bills and other documents incorporated in the 
Contract Documents, unless expressly stated to be excluded in any of the Contract Document. The Contractor is likewise responsible to provide materials and goods as described. On top of that, the Architect's requirement is to be fulfilled since he is the named contract arbiter of quality. Also, to prove that the supply of materials by a third party is of required quality, vouchers are to be supplied to prove the same, when requested by the Architect. The term when requested allows a form of liberty on the Architect to check whenever he wishes.

On the other hand, CIDB form adds on not only the material, goods and workmanship but also the equipment for quality control. The quality is again defined in the contract or to meet the requirement of the Superintending Officer (SO). Instead of expecting vouchers or certificates from test, the CIDB defines that tests are to be carried out at the place of manufacture. The proof of such tests is implied to have been certified.

CIDB forms also maintain that quality plan is to be prepared for submission to the SO within 14 days of the Letter of Award. Based on this quality plan, the methodology of works can be monitored for its execution and completion according to the Contract. The quality plan is to be reviewed for approval by the SO. The submission of the quality plan does not translate to the ability of Contractor to discharging his responsibilities under the Contract.

Clause 15.3 in CIDB form requires the Contractor to provide samples to the SO before making use of the same into the Works. The cost of providing these samples are to be borne by the Contactor, unless mentioned otherwise.

In FIDIC form, the contractor is to ensure that the plant, materials and all works are to be done is a manner that is specified in the contract, which is of recognized good quality and safe. The Contractor is to submit samples of Materials for approval before being used in the works. The cost of providing these samples will be borne by the Contractor unless additional samples are requested by the Engineer by with it will be considered a Variation. A quality assurance system is to be provided by the Contractor as a means for the Engineer to check the quality of Works of the Contractor. The system should contain the procedures and standards so that the compliance of the Works done can be checked.

\subsection{Testing and Inspection}

Clause 35.2 in PWD 203A form requires the Contractor to provide samples of materials or goods to be incorporated into the Work for testing at his own cost. It sanctions the Superintending Officer (SO) to demand the Contractor to open up any covered work in order to prove its compliance to the Contract. The cost of opening up and making of good can be added into the Bills of Quantities (BQ) or added into the Contract Sum, if not provided in the BQ. Should the test show disconformities, then the Contractor shall bear all cost of making good such repairs.

The Contractor is to submit a proposal or method statement for inspection of design and work progress, tests and workmanship to the SO for his approval. This fulfills the obligation under the Contract in Clause 10. The Contractor is to carry out the inspection and test approved under Clause 36.5 or elsewhere mentioned in the contract. This test may involve the SO as he reasonably requires; opening up covered works for inspection. The SO may then instruct the Contractor to remove or rectify such works which are not in accordance to the Contract at his own cost. Unless provided in the Contract, the cost of test shall be borne by the Contractor if it is proposed by the Contractor or the Contract clearly states that the Contractor is to bear the cost. Although test is requested by the SO, the Contractor will have to bear the cost of such should incompliance is shown. Otherwise, the Government will bear the cost.

In the PAM form, before including into works, the Contractor is to provide samples of materials for verification. The Architect may ask to open up works to inspect any covered i.e. included works to test. He may also request for testing on Materials or Goods which have been incorporated into the Works. The cost of such test will be included into the Contract Sum unless it has been provided for in the Contract Bills, inconsistencies of materials and goods are proven or such a test was (in the opinion of the Architect) required but was neglected due to the fault of the Contractor. This duty does not translate to allowing the Contractor to neglect Works. He will have to proceed with his works diligently as per the Contract. Should the work, materials, goods or workmanship be found to be not in accordance with the Contract, the Architect (in writing) may either instruct such materials to be removed from Site or deny entrance; or the Contractor should demolish and reconstruct such works in accordance to the Contract; rectify works as instructed by the Architect without adjustment to Contract Sum and to submit a method statement of rectification within seven days to be approved by the Architect; or to leave the works as it is with the Contractor remaining liable. The work which is left will be set-off by the Employer. Any abidance of the above in Clause 6.5 does not translate to granted extension time of compensation.

In CIDB form, the contractor will bear the cost of tests if it is as mentioned in the contract or if additional test were required as a result of prior failure or other negligence by the Contractor. The Employer will bear the cost of the tests if the same was not intended in the Contract or the venue of the test was changed other than it was intended for. Should the test show unconformities, then Contractors will bear the cost of the test. When the cost of such test is to be borne by the Employer, it will be in the form of Variation of the total Sum of the cost of project.

Works should not be covered up unless attaining approval from the SO to do so. The Contractor shall provide sufficient allocation for the SO to examine and measure any part of the Works which is about to be covered up. The Contractor should 
notify the SO of the works which are ready or almost ready for inspection. If the SO in writing expresses that there is no need for such examination, then the Contractor may proceed with his Works. If the Contractor fails to gain approval before covering the Works as per Clause 15.5, the SO may request the Contractor to open such works and the cost of opening and later restoring the works shall be borne by the Contractor; whether or not the Works are in accordance to the Contract. This additional work does not give rise to any extension of time since it is caused by the Contractor's negligence. The Contractor will also have to bear any additional cost with regards to the aforementioned Works as instructed by the SO.

The SO may still require the Contractor to uncover any parts of the Works at any time and also instruct the Contractor to remedy the Works to his satisfaction. Should the Contractor have abided by sub-clause 15.5 (a) and (b), by notifying the SO of Works before covering up, then the cost will be borne by the client in terms of Variation, since it is an additional work by no fault of the Contractor.

In the FIDIC form, the Employer's Personnel (i.e. the Engineer and his staff assistants) should be given full access to the Site and where resources of material are being procured. This should apply at all phases of Works be it the production, manufacture or construction, where the Employer's Personnel may inspect, measure or test the materials and workmanship. On top of providing opportunity, proper access road, facilities and safety equipment is to be allocated.

The Contractor is required to give notice to when any work is ready for inspection, before it is put out of sight. The Engineer shall then carry out proper inspection, measurement or testing. Should the Engineer, in his opinion do not require carrying out the aforementioned inspections, then he should immediately inform the Contractor. If the contractor fails to give notice in the first place, then any the cost to uncover and restoring the condition will be borne by the Contractor.

All the resources to carry out the tests shall be provided by the Contractor. This includes equipments, assistance, documents, consumables labour and qualified staff. The time and place of testing shall be arranged and agreed upon by the Contractor.

The Engineer may change the location or the details of a specified test or perform additional test. If these additional tests show that Plant, Materials or Workmanship does not conform to the Contract then the cost of carry out this additional test (or Variation) will be at the Contractor's cost even if there are other provisions in the Contract for such a Variation.

The Engineer should inform the Contractor in not less than 24 hours notice that he intends to attend a test. Should the Engineer not attend the test at the agreed time and place, then the Contractor may proceed with the test and it is deemed to have been witnessed by the Engineer unless the Engineer gives another instruction. If delay is incurred by abiding by any instructions or by fault of the Employer, then the contractor shall give notice to entitle him of an extension of time and additional payment with reasonable profit. Upon receiving the notice, the Engineer shall proceed with the claims according to Sub-Clause 3.5 to agree with an amount of claim.

The Contractor shall provide the certified reports of the test to the Engineer. When the test is passed, the Engineer should endorse the Contractor's test certificate. The Engineer is to accept readings as accurate even if he did not attend the test. Upon examination, inspection or measurement, should any defectiveness not according to the Contract be detected, the Engineer may reject the Plant, Materials or workmanship by issuing a notice with explanations. The Contractor should then immediately restore the defective works in accordance to the Contract. At the request of the Engineer, retesting of the Plant, Materials or workmanship is to be performed. If the rejection and retesting incurs cost on the Employer, then the Contractor shall pay this cost to the employer as per Sub-Clause 2.5.

In spite of any test of certification, the Engineer may still instruct the Contractor to remove or replace defective Plant or Materials which are not in accordance to the Contract. The Engineer may also instruct the Contractor to remove and redo works which are not in accordance to the Contract. Instruction to execute works which are urgently required for the safety of Works may also be issued by the Engineer for unforeseeable circumstances such as accidents.

\subsection{Performance Bond}

In PWD 203A 2007 Form, the Performance Bond will be provided at the date of site possession via an approved licensed bank or financial institution. The Government should be the beneficiary of this Bond amounting to 5\% of the Contract Sum. The Bond should remain valid for an additional 12 months after the expiry of, whichever the latter, the Defect Liability Period or the issuance of the Certificate of Completion of Making Good Defects. Failure of the Contractor's submission of the Bond on time would automatically translate to the Contractor opting for the Performance Guarantee Sum. An amount of $10 \%$ will be deducted from every earlier interim until the said $5 \%$ of the Contract Sum is attained. Like the Performance Bond, the validity of this Performance Guarantee Sum will apply.

The Client has the right, at any time, to call upon the either the whole sum of the Bond or part of it, when the Contractor fails to perform his obligations and does not remedy that failure. When a payment is made via the Bond to the Government, the Contractor should add on to the amount of the Bond to retain the actual initial amount as specified earlier. 
After the validity period, i.e. after the Contractor as done all the necessary repairs within the twelve month period, the Bond or its balance will be refunded to the Contractor. If in the case of Contract termination in the default of the Contractor under clause 51, the Bond or its balance will be forfeited and belongs to Government.

PAM form explains that the Performance Bond should be submitted to the Employer by the contactor before the Date of Commencement of Works. The amount would be agreed upon as per the Appendix. The terms of the Performance Bond will be as stated in the Contract or if not stated, will be subjected to the approval of the Employer.

The Bond shall remain valid until three months after the Completion Date. Should the works be not completed by the Completion Date, then the Contractor should extend the duration of the Bond to expire three months after the projected Practical Completion of Works. Failure of the Contractor to provide or maintain the Bond gives the Employer the right to withhold or deduct an amount of payment due to the Contractor equal to the Performance Bond.

In the event of Employer determination as per Clause 25.0, or in the event of breach of Contract, the Employer may call upon the Bond for the rectification and reimbursement of losses incurred by the Employer. The balance if any would be returned to the Contractor on the Completion of the Works without interest. Should the Contractor determine his own employment as per Clause 26, the Employer should within 28 days return the Performance Bond to the Contractor.

CIDB form maintains that the Performance Bond should be provided to the Employer as per the amount stated in the Appendix within 14 days of the letter of Award, before the commencement of Works. The Bond will be used as a security of performance and observance of the Contract by the Contractor. The Bond may be in the form of cash, banker's draft, a banker's bond or all insurer's bond as per the requirement of the Contract or approved by the Employer in the case where it is not mentioned in the contract.

The Employer will hold the Bond until the issue of the Certificate of Practical Completion by the Superintending Officer as per Clause 20.2. If the Bond is in the form of banker's bond or insurer's bond, the Contractor should maintain the validity of the Bond until the issuance of the Certificate of Practical Completion. Failing to do so, the Employer may withhold an amount equal to the amount of the Bond which is due to the Contractor, until the issuance of the Certificate of Practical Completion.

If the Contractor fails to perform as per the Contract or commit any breach of his obligation, then the Employer may make use of the Bond to make any necessary payments as per sub-clause F3(b) and F3(c). The S.O. issuing of a notice of default to the Employer with a copy to the Contractor is a prerequisite to make use of the Bond. The notice should state that the Contractor has failed to execute the Works or breached in his obligation under the Contract, and the way he as failed to do so, together with an estimate of the cost, damage, loss or injury to be paid to the Employer. Should the cost of the aforementioned damages be more than the Bond, then the Employer has the right to withhold any certified payments.

Upon the issuance of the Certificate of Practical Completion by the Superintending Officer., the Bond or any balance of it should be refunded back to the Contractor. In the event that banker's bond or insurer's bond be used, it will have no effect after the issuance of the Certificate of Practical Completion.

In FIDIC performance bond is placed under a sub-clause that will not be in effect if an amount of the Performance Security (Bond) is not stated in the Appendix to Tender. Otherwise, the Contractor shall provide the said Bond as per the Appendix within 28 days of the receipt of Letter of Acceptance, and submit a copy of the Bond to the Employer. The Bond will be issued by an entity authorised by the Employer. The Contractor should ensure that the Bond is valid until the completion of Works and remedy of defects. If the terms are to expire i.e. within 28 days of the expiry and the Contractor still has yet to receive the Performance Certificate, then he should extend the validity of the Bond until all Works are completed and defects have been remedied.

The Employer can only call upon the Bond, if, the Contactor fails to extend the validity of the Bond; failure of the Contractor to pay an amount due to the Employer; failure of Contractor to remedy any default within 42 days after receipt of notice from the Employer; or termination by the Employer as per Sub-clause 15.2. Any losses incurred by the Employer shall be indemnified against the Contractor as a result from the claim of the Bond, by which the Employer was not entitled to claim. The Employer should return the Bond within 21 days of the receipt of the copy of the Performance Certificate.

\subsection{Disputes}

With exception of PWD, other forms under study suggested also alternative dispute resolution methods such as mediation on top of arbitration. PAM form has also taken to include adjudication as an option. Instead of providing options, CIDB and FIDIC provide a guideline of steps to be taken; option after option should each ADR method fail leading towards arbitration. This gives proper direction to each party so that no party will unilaterally go for arbitration without the other party's consent.

The results from the above analysis points towards inadequacy of quality provision in standard form of construction contracts among the forms studied. The summary comparison is displayed in the Pugh Analysis as shown in Table 1. 
Developed by Stuart Pugh, University of Strathclyde, Glasgow, it is a simple method of decision making tool when there are limited amount of data. Each criterion is weighed based on their significance to the latter product; i.e. in this case quality on site. The analysis done for this test will involve rating of 1 to 5 , as per follows:

$$
\begin{aligned}
& 5 \text { - Highly meets criterion } \\
& 4 \text { - Adequately meets criterion } \\
& 3 \text { - Marginally meets criterion } \\
& 2 \text { - Slightly below criterion } \\
& 1 \text { - Below criterion }
\end{aligned}
$$

Each criterion is also adequately weighed based on its significance or impact on quality from 1 to 5 as well.

Table 1: Pugh Analysis for the adequacy criteria among standard forms

\begin{tabular}{|c|c|c|c|c|c|}
\hline Criterion & Weight & PWD & PAM & CIDB & FIDIC \\
\hline Adequacy & & & & & \\
\hline - Material \& Workmanship & 5 & 3 & 3 & 5 & 4 \\
\hline - Testing \& Inspection & 4 & 3 & 3 & 3 & 3 \\
\hline - Performance Bond & 3 & 4 & 4 & 3 & 3 \\
\hline - Dispute Resolution & 2 & 1 & 2 & 4 & 5 \\
\hline \multicolumn{2}{|r|}{ SCORE }
\end{tabular}

\section{DISCUSSION}

Stakeholders from the construction industry in Malaysia have always been championing the concept of an-one-size-fit all standard forms of construction contract for all projects. Looking at the various new forms introduced and the old ones revised and revamped, Malaysia has a somewhat big numbers of standard forms. Many of the standard forms used in the country have been drafted based upon old British contract forms save for the new CIDB Contract released in year 2000, which is one radically different form. Even though, with over 50 years of independence and the successful completion of numerous projects via the usage of standard forms, Malaysian standard forms are not without its flaws and shortcomings.

Recent events of quality mishaps in the construction industry have led to the question of accountability of the engineers and the contractors, as a whole. The mismanagement of contracts has been allegedly the key to this issue, save for any tortuous or criminal act [13]. In standard forms of construction contracts Material and Workmanship clauses form a preemptive measure to quality control on site. The provisions intend to cater for all possible quality aspects before any Material is included into the Work or even before the Work begins. All the forms denote that the Contract Document or more precisely the Specifications, will spell out the standard by which the Contractor should abide. Thus, the need for a secondary reference point in a contract arises and is often provided not only the Specifications but also 'Special Conditions or Clauses'. Usage of secondary references like "Special Conditions", "Specification" paved way for dangerous practice of one-pointlacking-covered-by-another, which renders the clauses confusing and thus departing from the principle of forms not subject to amendments and negotiations. Tendency to amend clauses in an ad-hoc and invalidated piecemeal fashion through the provision of secondary references gives rise to further confusion.

From the study carried out, it is seen that the inadequacy of standard forms, specifically with the Material and Workmanship provisions, has led to what [1] mentioned, the tendency of multiple interpretations. Many phrases used in the common standard forms can be deemed as ambiguous and lack clarification. For example, in the PWD and PAM form, it was found that quality should be that of the "standard of the industry". Although its intention is to provide for the latest i.e. the best quality product or service available at the time of construction, it still does not justify creating such an obscure provision. In FIDIC, the term "proper workmanlike" and "recognised good practice" is very subjective as well. [12] also agrees that such phrases are not precise and will eventually lead to the requirement of the Engineer's interpretation. Therefore, terms like these are of no contractual value and are deemed redundant.

Should the provisions and the other points of reference in the contract still could not fully clarify the course of actions that can be taken for problem solving, the Contract Administrator will then step in to clear any doubts. The PAM, CIDB and FIDIC forms clearly state that the Contract Administrator will be the arbiter of quality while the PWD form only implies that it is via the duty of the Superintending Officer. Nonetheless, all of the forms, whether explicitly or otherwise, provides for the Contract Administrator as the arbiter of quality.

Although the Contract Administrator is to act in his capacity as per the provisions of the Contract, elements of subjectivity is likely to occur, since the Contract Administrator's instructions serve to complement the provisions and any secondary point of reference. These provisions ultimately place power and thus, possibility of subjectivity onto the arbiter. However, 
according to the respondent from the interview, the element of check is reviewable via arbitration which will be discussed further in the subsequent section.

Most forms adopted the straightforward method to ensure quality assurance by requesting for vouchers or certificates. Even when the certificate is provided by the suppliers, the Contractor is responsible for such materials. Should materials are later discovered to be faulty, the Contractor is still liable (vide Young \& Marten Ltd v McManus Childs Ltd [1969] 1 AC 454). The vouchers seem to be an inconclusive method of quality assurance since the Contractor is still subject to further inspection.

A quality plan entails the steps that are to be taken by the Contractor to ensure quality on site. It therefore, is an indirect 'promise' that the Contractor will abide by the said steps and the Contract Administrator will then monitor the Contractor's work based on the project quality plan (PQP) submitted to him. But not all standard forms request specifically for a PQP or provide a standard for it. According to the respondents, the PQP is a common practice especially in big projects that are worth more than RM 10 million.

From the results of the clause study, it is seen that Testing and Inspection provisions can be further improved in terms of adequacy. Most provisions are amply filled with the obligations of cost and most of the time; the Contractor will bear the cost, unless it is by the default of the Employer. This also becomes the 'rule of thumb' when studying these clauses, since most of the forms, especially PWD and PAM remains silent on certain issues and obligations.

The power to instruct to uncover Works is at the Contract Administrator's absolute discretion. It is justified to have the Contractor bear the cost of opening and later making good of the Works should there be any inconsistence in the Work quality. Conversely, should no discrepancy be detected, the cost will be added to the Contract Sum in the form of a Variation. Only the CIDB and FIDIC clearly states the part on the Variation, i.e. the allocation of liability that should be borne by the Employer. Although it can be implied, both PWD and PAM are silent on this matter. Subsequent to any defaults detected, the Contract Administrator has to order for their removal as per Holland Hannen \&Cubitts(Northern) Ltd $v$ Welsh Health Technical Services Organisation (1981) 18 BLR 80.

The CIDB and FIDIC go further with the need to notify the Contract Administrator before any Works is covered up. This then significantly reduces the need to open up the Works later, although the Contract Administrator may instruct to carry out this costly works at any time. Despite the fact that it is a common practice to inform the Contract Administrator before covering up, the Contract should likewise state so. Consequently, if the Contractor does not inform the Contract Administrator prior to covering up, the cost of any opening up of the works later on will be borne by the Contractor.

However with this notification, CIDB and FIDIC also explicitly allows for the Contract Administrator to be absent from any testing and inspection work. He is also to deem the readings taken to be accurate. This flaw is observed. It is indeed arguable that during the course of the project, the Contract Administrator or his representatives will inevitably be busy and to save time, this provision is given. The Contract Administrator is, nevertheless the arbiter of quality and such duties should not be neglected.

When it comes to assuring quality on site, the Engineer or his representative should witness all the tests. As one of the respondent insisted, he is after all the arbiter of quality. As reliable as the Contractor might be, the tests should be witnessed either by the Contract Administrator or his representative/s. Therefore, this provision is questionable, should quality be put as priority. Often, when time is of essence, this clause is enforced and quality is often compromised here. Ironically, the inadequacy here is not caused the absence of this provision but rather the existence of the same which sanctions the Contract Administrator to be absent during tests.

Performance bond clause serves as a leverage to negate risk that the Contractor might choose to abandon his Works or any of his obligations. All forms have clauses related to this but with the exception of PWD; no actually amount is stated in the other forms. The usual sum of $5 \%$ of the entire Cost of the project is a big sum considering that many projects run in the millions and billions of ringgit. And the Contractor would not just deliberately lose that sum of money. As the respondent mentioned, "The common practice is for the superintending officer [Contract Administrator] to not certify that work for payment and issuing instruction to rectify; failing which to engage a $3^{\text {rd }}$ party to rectify and recover the payment from the Contractor."

The failure by the Contractor to submit the Performance Bond is a breach of conduct and entitles the Employer to discharge the Contractor and sue for damages accordingly (vide Swartz \&Son (Pty) Ltd v Wolmaransstad Town Council 1960 (2) SALR 1). Technically, the Contractor is not supposed to begin Works unless he has presented the Bond. This however is often not the case, rendering such provisions in the forms ineffective.

Disputes can be simply defined as being anything that the parties disagree on. The types of dispute resolution can largely be divided into two, "Hard" and "Soft". Hard being arbitration and litigation and soft being the otherwise for example, mediation, conciliation and the like as mentioned by the respondent. Alternative dispute resolution (ADR) as described as the soft resolution is gaining momentum in many countries [8]. 
From the study, it is seen that arbitration is a common dispute resolution covered by all the standard forms in this study. It is more advantageous to that of litigation since the number of countries that have entered into treaties with Malaysia for the reciprocal enforcement or arbitral awards is greater than that of Court Judgements. The current method of arbitration is increasingly too expensive and too slow. Therefore the need of ADR is greatly felt. A good dispute resolution method will ensure that existing problems on site will lead to a good remedial method and hence quality on site. Further, it is desirable to have a swift dispute resolution procedure to contemporaneously determine the quality issue and this is via adjudication as recorded from the semi-structured interviews.

In summary it is clearly seen from the common forms that all cover different quality issues in differing depths and extent. This brings on board inconsistency across the forms, which would hinder contract administration especially if the parties of the contract are familiar with one or two specific forms only. With the existing inadequacies in the quality provisions in standard forms studied, topped with the stakeholder's lackadaisical attitude towards contract interpretation, the standard forms of contract are often literally left in the drawer, allowing decisions to be arbitrarily made based on past experience. The undeniable fact is that a great number of these projects have been successfully accomplished without having to refer to standard forms [2]. Nonetheless, when things go wrong, the blame would necessarily become an issue, since no party would step up to the plate [1].

\section{CONCLUSION}

There is a need to adequately cater for quality provisions and also a need to delete ambiguous terms and conditions as being highlighted in the discussion earlier in order to account for quality on site. The fact that the forms lowly rated in this study i.e. PWD and PAM form; signifies that there are other reasons not covered in this study that allow the survival of these forms. The PWD form is the undisputable de facto form used in public works and is also approved for use by the Attorney General's Chamber. This is therefore a political leverage for the usage of the PWD form.

As for PAM which dominates private projects, the factor of familiarity perhaps becomes significant. Engineers, Employers and Contractors alike, feel more secure using forms that they are used to. According to one of the respondents, there are some small projects which are still using the PAM/ISM 1969 Form of Contract, the predecessor of PAM 1998. This then points out the problem with the attitude of the users in the industry. Also, since architects are the ones who usually lead a building project, they will most likely adopt the PAM form in support of their association.

The FIDIC form also has a political leverage since internationally funded projects by World Bank and other multilateral development banks ratify the FIDIC form. Therefore projects funded by them will most definitely use the FIDIC form. This however is not an indication that the FIDIC form is of poor quality. There, however is room for improvement, especially for localised usage.

The CIDB unfortunately is the least used amongst all, despite having best rated in this academic analysis. Due to the reasons above, the CIDB form is hindered from being used widely, since all the sectors are being taken up, be it public, private or international.

\section{REFERENCE}

[1] Barnes, M. (198). Construction Project Management. International Journal of Project Management, Volume 6 (1988); pp69-79

[2] Broome, J.C. \& Hayes, R.W. (1997) A Comparison of the Clarity of Traditional Construction Contracts and the New Engineering Contract International Journal of Project Management, Volume 15(1997); pp 255-261

[3] Chan, M.Y.L. (2006). New Engineering Contract (NEC) 1993 as Radical Changes to the Malaysian Standard Forms of Contract. Masters Thesis, Universiti Teknologi Malaysia.

[4] Jannadia, M. et al (2000). Contractual Methods for Dispute Avoidance and Resolution (DAR). International Journal of Project Management, Volume 18 (2000); pp 41-49

[5] Lim, C. F. (2004). The Malaysian PWD Form of Construction Contract. Malaysia: Sweet \& Maxwell Asia

[6] Mohamad I.M. (2006). Understanding Contract Documentation. Malaysia: Proceedings of the 6th Asia-Pacific Structural Engineering and Construction Conference (APSEC 2006).

[7] Ong, S.L. (2008). PAM Contract 2006 - Overview and Salient Clauses. Malaysia: Davis Langdon \& Seah

[8] Oon, C.K. (2002) Standard Construction Contracts in Malaysia. CKOON \& Co. Advocates and Solicitors

[9] Oon, C.K. (2008) Understanding Construction Contracts. Institute of Engineers, Malaysia

[10] Rajoo, S. (1999). The Malaysian Standard Form of Building Contract (The PAM 1998 Form). $2^{\text {nd }}$ ed. Malaysia: Malayan Law Journal 
UNIMAS E-Journal of Civil Engineering, Vol. 1: issue 1 /August 2009

[11] Tay, L.Y. (2006). Determination of Contract by Employer in Construction Industry. Masters Thesis, Universiti Teknologi Malaysia.

[12] Totterdill, B.W. (2001). FIDIC users' guide - A practical guide to the 1999 red book. $1^{\text {st }}$ ed. London: Thomas Telford

[13] Wahid, O. (2006) MRR2: Engineers Could Not Speak Up? Jurutera, Issue April 2006; p38

[14] Wright, J. N. \& Fergusson, W. (2009) Benefits of the NEC ECC form of contract: A New Zealand case study. International Journal of Project Management, Volume 27 (2009); pp 243-249

[15] Young \& Marten Ltd v McManus Childs Ltd [1969] 1 AC 454

[16] Holland Hannen \&Cubitts(Northern) Ltd v Welsh Health Technical Services Organisation (1981) 18 BLR 80.

[17]Swatz \&Son (Pty) Ltd v Wolmaransstad Town Council 1960 (2) SALR 1 